\title{
Statistical assessment of injection aparatus of diesel
}

Wiktor Kupraszewicz ${ }^{1, *}$

${ }^{1}$ Stanisława Staszic State Higher School of Vocational Education in 64-920 Pila, Poland

\begin{abstract}
The issue of estimating technological condition of internal combustion engine gathers special meaning mostly in using stage, in consideration of economic and ecological conditions. Appliances which are used now a days and which diagnose condition of subjects such as compression - ignition engines, are limited only to the measurements. This article discusses problems of methods diagnosis with special regard of fuel apparatus.
\end{abstract}

\section{Introduction}

The condition of injection apparatus of the ICE primarily determines its correct operation. Based on many studies of Diesel engines, it was concluded that the damage initiated by maladjustment starts first in the fuel supply system, especially in the high pressure systems of the injection apparatus $[8,9,10]$. Every case of failure of the injection pump or the injector causes engine revolution drop which leads to the faster use and serious failures. Therefore, even more important in diagnosing Diesel engines are installation-free methods consisting in the early identification of inoperable elements of injection apparatus.

The low repeatability of fuel pressure parameters in the injection conduits (Fig. 1) being a cycle of complex, independent wave phenomena, seriously complicates the diagnosing with comparative method and requires high perception from the operator which often exceeds his capabilities $[3,8,9,10]$.

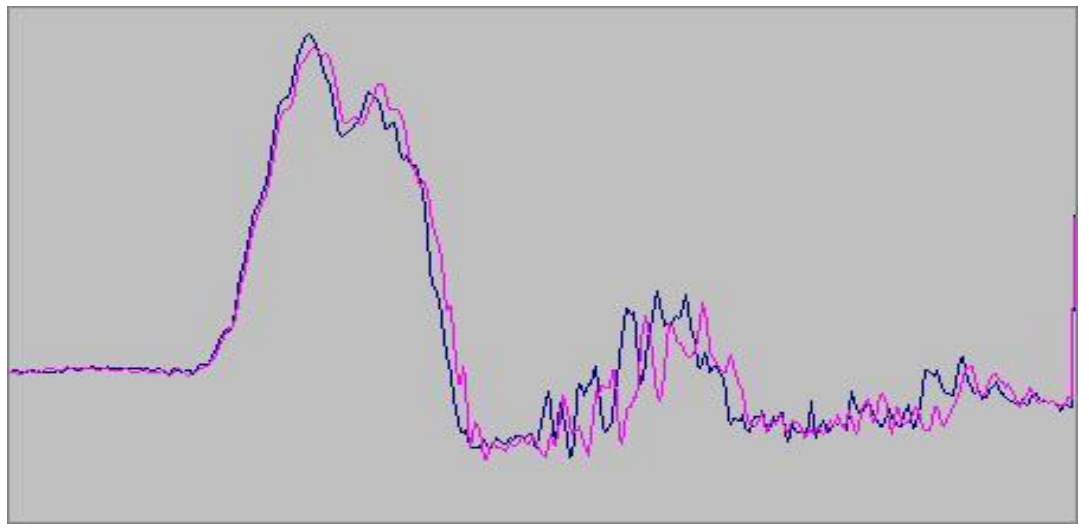

Fig.1. Two fuel pressure oscillograms in injection conduit measured in different time intervals for working apparatus.

In order to identify maladjustment and failure of engine systems in the operation of UTD-20 engines (high repair cost) as early as possible, an attempt was made to fit the existing diagnostic tool (Diesel engine tester), developed at the Department of Working Machines and Vehicles, Technical and Agricultural University in Bydgoszcz, into the operator support sys-tem - advisory system.

${ }^{\star}$ Corresponding author: wkupraszewicz@pwsz.pila.pl 


\section{Concept of advisory system}

The advisory system $[2,5,7,11]$ to support Diesel engine tester's operator was provided based on the skeleton system. The skeleton system "Exsys Developer v8.0" by MultiLogic operating under Windows 9x was chosen to develop the advisory system prototype. The system has built-in mechanisms to create knowledge databases which is represented as rules.

The architecture of the system (Fig. 2) includes the following basic elements:

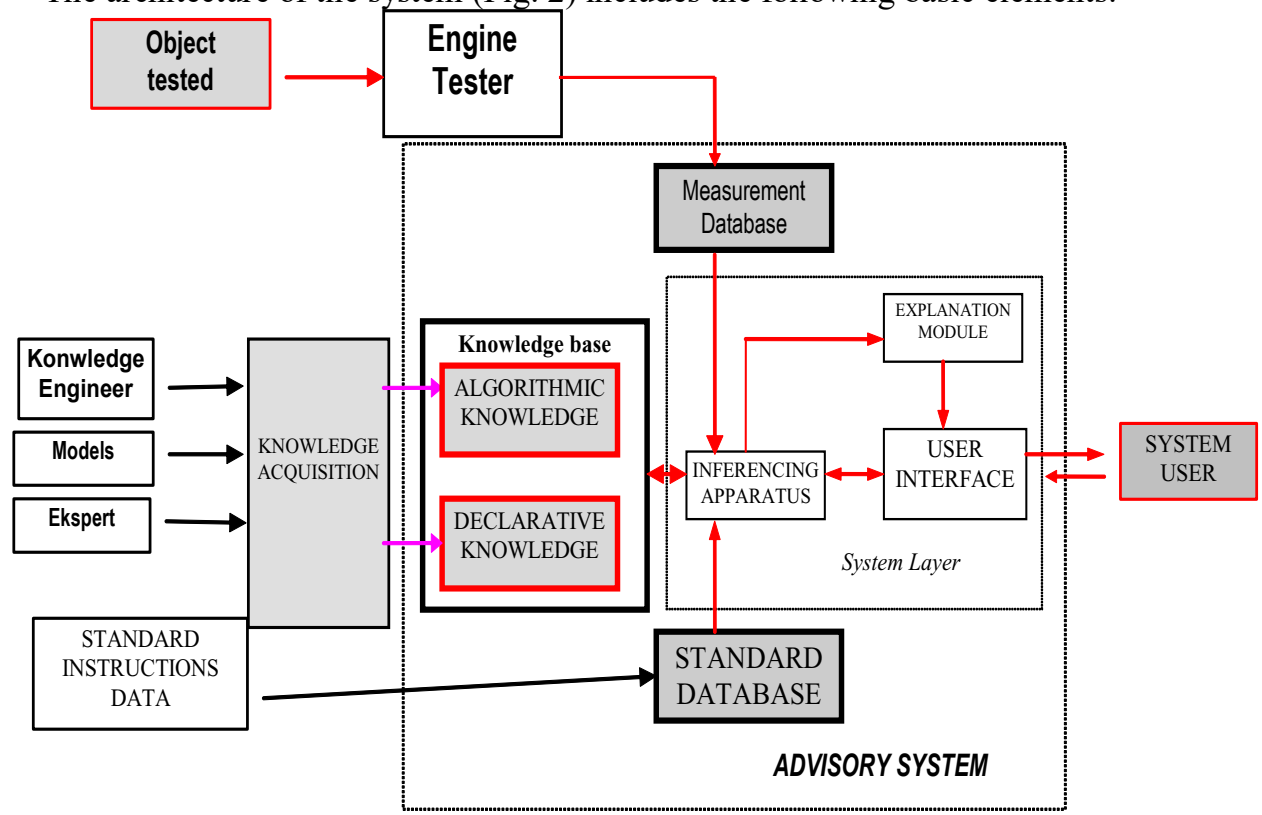

Fig. 2. Architecture of advisory system supporting operator's decisions based on tester measurement [5]

- Knowledge database - its source is knowledge from experts, operation instructions and UTD-20 engine tests - recorded as inferencing rules;

- Database - set of operation characteristics such as: fuel injection angle, crank-shaft rotary rate on idle run, electric voltage and accumulator amperage during start-up, model fuel pressure oscillograms in injection conduit and the data from operation tests and instructions being fixed data and measured data entered by the operator during engine test being variable data;

- Inferencing procedures - defined as dialogue control algorithm, saved in the sys-tem and updated by the knowledge engineer;

- Explanations - inform on the inferencing strategy, allow to explain during knowledge database updating why a given solution is chosen;

- Dialogue control procedures - input / output procedures to formulate questions and give answers by the operator, and provide the solution as a report;

- Modules to extend and modify database.

Given the complex nature of the phenomena accompanying the fuel pumping and injection, the neuronal computer vision classifier was abandoned. Few tests conducted within identification of injection apparatus with the use of artificial neuronal network (despite more frequent uses in the technical diagnostics) confirm certain limitations in their use in this case. These limitations refer to, among others, the type of network, its computer form and calculation capacities. 
Since the skeleton used for design has no tool in the form of, for example, artificial neuronal network, which can be used to identify the pressure oscillograms (most often identification of the injection apparatus is done by the tester operator), the following oscillogram solution was proposed (Fig. 3) consisting in assigning the oscillogram monitoring to the specific class.

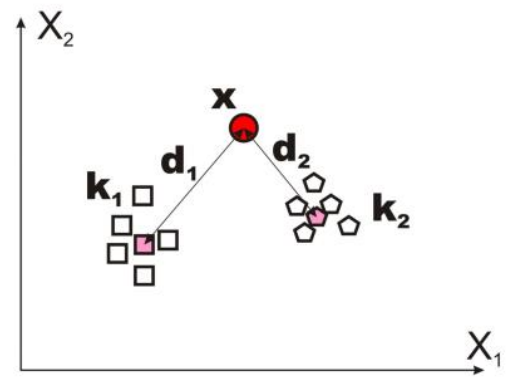

Fig. 3. Classification of oscillogram observations according to nearest neighbour [1].

The system user saves the pressure oscillograms in text files compatible with ASCII. A file is imported into MS Excel, where a recorded value is classified into one of the classes: class 1 - engine injection apparatus is good; class 2 - injection apparatus not working, injector spring damage; class 3 - injection apparatus not working, leaking injector nozzle. Based on the identified and classified recorded value into class (number $1,2, \ldots \mathrm{m}$ ) and placing it into the advisory system, a finding is generated as a result of identification of the injection apparatus.

\section{Statistical decision-making criterion}

Statistical decision-making criterion is based on Bayes recognition algorithm [1,5]. Let $\mid \mathrm{P}$, where $\mathrm{P}$, the dimension of characteristics vector is the space of observation. Let $\mathrm{M}$ be the space of classes and (to simplify) the decision space. For the given (or estimated) probabilities, observation (image) $\mathrm{x}$ from given class $\mathrm{m}$ appears, that is $\mathrm{P} 1, \mathrm{P} 2, \ldots \mathrm{PM}$, and for the given estimated distributions of density $\mathrm{M}$, conditional probabilities $\mathrm{Q}(\mathrm{x} \mid 1), \mathrm{Q}(\mathrm{x} \mid 2)$, $\ldots \mathrm{Q}(\mathrm{x} \mid \mathrm{M})$ (Fig. 4.), the statistical recognition consists in assigning to a random image $\mathrm{x}==$ $\left(\mathrm{x}_{1}, \mathrm{x}_{2}, \ldots, \mathrm{x}_{\mathrm{p}} \ldots, \mathrm{x}_{\mathrm{M}}\right) \in \chi^{\mathrm{P}}$; the decision on affinity to one of the classes.

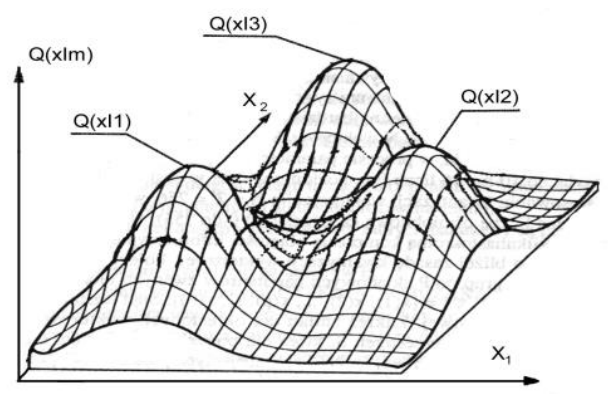

Fig.4. Distribution of conditional probabilities density for $\mathrm{M}=3$ classes.

Function $\Psi(x)$ for which we call image $x \in m$ as decision rule.

Introducing the concept of medium risk $R(\Psi)$ :

$$
\mathrm{R}(\Psi)=\mathrm{R}_{\mathrm{m}}(\mathrm{x})=\sum_{l=1}^{M} c_{m, l} P(l / x),
$$


where: $\mathrm{cm}, \mathrm{I}$ - element of loss matrix which defines the loss value resulting from classifying an observation (image) from class 1 as belonging to class $\mathrm{m}$.

Since the probability $P(\| x)$ with which we recognize the image, represents class $m$, is related to the density of conditional probabilities, Bayes dependence:

$$
\mathrm{P}(\mathrm{m} \mid \mathrm{x})=\frac{Q(x / m) P_{m}}{\sum_{l=1}^{M} Q(x / l) P_{l}} ; \mathrm{m}=1,2, \ldots, \mathrm{M}
$$

And considering the fact that for a given image $x$ the denominator of dependence on $\mathrm{P}(\mathrm{x} \mid \mathrm{m})$ is fixed, the dependence for medium risk can be brought down to the form:

$$
\mathrm{R}_{\mathrm{m}}(\mathrm{x})=\sum_{l=1}^{M} c_{m, l} Q(x / l) P_{l} .
$$

Therefore, Bayes recognition rule $\Psi(x)$ has the following form:

$$
\Psi(x)=m \text { i.e.. } x \in m
$$

if:

$$
\mathrm{R}_{\mathrm{m}}(\mathrm{x})<\mathrm{R}_{1}(\mathrm{x}) ; \text { for } \Lambda_{k \neq l} ; \mathrm{k}=1,2, \ldots, \mathrm{M} .
$$

The situation where we know the values of all distributions is ideal and virtually does not occur. Many recognition systems are based on the simple idea to assign an observation to the nearest class. The non-parametric recognition algorithms has specific relations between two observations (images) or between an observation and its standard of a given class, known as similarity functions. They are the measure to provide the decision rule. The similarity functions may occur as a distance function (known as distance in short) or a proximity function. The most common algorithms using this classification method include:

Nearest neighbor method (used as a classifier in the form of macro);

\begin{tabular}{|c|c|c|c|c|c|c|c|c|c|c|c|c|c|c|c|c|c|c|c|c|c|c|}
\hline & & & & & & & & & & & & & & & & & & & & & Przy & pisane \\
\hline 11 & 19 & 11 & 0 & 5 & 13 & 7 & 1 & -5 & -10 & -11 & -15 & -21 & -21 & -12 & -5 & -6 & -20 & -20 & 3 & 12 & 1 & \\
\hline 13 & 9 & 8 & 4 & 9 & 15 & 9 & -1 & -1 & 2 & -3 & -15 & -25 & -30 & -45 & -54 & -41 & -32 & -30 & -22 & -8 & 1 & \\
\hline 10 & 19 & 11 & -1 & 5 & 12 & 6 & 2 & -4 & -10 & -11 & -15 & -21 & -21 & -12 & -5 & -6 & -20 & -20 & 3 & 12 & 1 & \\
\hline 12 & 15 & 6 & 5 & 8 & 14 & 10 & -1 & -3 & 2 & -4 & -15 & -25 & -34 & -46 & -54 & -41 & -32 & -30 & -22 & -8 & 1 & \\
\hline-23 & -12 & -7 & -6 & -7 & -7 & -8 & -11 & -8 & -4 & -3 & -6 & -13 & -15 & -14 & -14 & -16 & -14 & -7 & -15 & -26 & 2 & \\
\hline-13 & -6 & 0 & -4 & -8 & -8 & -7 & -10 & -12 & -12 & -9 & -8 & -23 & -20 & -12 & -17 & -17 & -10 & -11 & -16 & -6 & 2 & \\
\hline-13 & -6 & 0 & -4 & -8 & -8 & -7 & -10 & -12 & -12 & -9 & -8 & -23 & -20 & -12 & -17 & -17 & -10 & -11 & -16 & -6 & 2 & \\
\hline
\end{tabular}

$\mathrm{K}$-nearest neighbors method (a modification of the first one)

$\mathrm{NN}$ algorithm (Nearest Neighbor) acts based on assigning a new observation $\mathrm{x}$ to the already known learning sequence classes (Fig.5.)

Wektory średnich w poszczególnych klasach

Klasa 1

Klasa 2

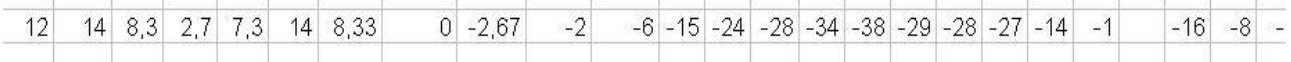

Macierze kowariancji w poszczególnych klasach

Klasa 1

Klasa 2

\begin{tabular}{l|l|l|l|l|l|l|l|l|l|l|l|l|l|l|l|l|l|l|l|l|l|l|}
1 & 0 & 0 & 0 & 0 & 0 & 0 & 0 & 0 & 0 & 0 & 0 & 0 & 0 & 0 & 0 & 0 & 0 & 0 & 0 & 0 & 1 & 0 \\
\hline 0 & 1 & 0 & 0 & 0 & 0 & 0 & 0 & 0 & 0 & 0 & 0 & 0 & 0 & 0 & 0 & 0 & 0 & 0 & 0 & 0 & 0 & 1 \\
\hline
\end{tabular}

Fig.5. Learning set composed of three model observations and recognized new observation (classified as class 1 ) 
In the process of proper recognition, a new observation (image) appears whose assignment to a specific class is unknown $\{x\} \in \chi P$. The procedure of $N N$ algorithm performs calculation of the similarity function (usually the distance) between all observations (images) of the learning sequence and the unknown (new) observation $x$ : where $W m, i=x(m, i)$.

$$
\mathrm{FP}\left(\mathrm{x}, W_{m, i}\right) \text { for } \mathrm{m}=1,2, \ldots, \mathrm{M}, \mathrm{i}=1,2, \ldots, \mathrm{I}_{\mathrm{m}}
$$

Upon calculation of all similarity functions, the lowest one is looked for (in case of distance) and as a classifier's decision, the name (cod) or class number to which the image of learning sequence belonged is given and which is the nearest in the sense of function of similarity to the recognized image:

if:

$$
\Psi(x)=m \text { i.e. } x \in m
$$

$$
\begin{gathered}
\mathrm{FP}\left(\mathrm{x}, W_{m, l}\right)<\mathrm{FP}\left(\mathrm{x}, W_{l, l}\right) \\
\text { for } \Lambda_{m \neq l} ; m, l=1,2, \ldots, \mathrm{M} .
\end{gathered}
$$

The nearest method despite considerable recognition time is characterized by high accuracy of recognition of $87.4 \%[3,6,7,10]$. Considering such criteria as: type of image (400 vectors Fig.1.), the calculation capacity of the equipment and available programs, recognition time and accuracy, a macro has been developed using the built-in Visual Basic module for MS Excel.

\section{Image recognition algorithm}

In the proposed solution as a similarity function, from many used in minimum-distance algorithms, the Euclidean distance was applied:

$$
d_{i j}=\sqrt{\sum_{k=1}^{p}\left(x_{i k}-x_{j k}\right)^{2}}
$$

Recognition algorithm and assignment of a new observation to a class is shown in Fig. 6.

Preparation of the learning set was done during tests of engines in the test room and consisted in recording oscillograms for engines after the main repair with a working fuel ap-paratus. Thus, a data matrix $\mathrm{X}_{1}$ belonging to class 1 was created. Next, by introducing further maladjustments and damage, recording of oscillograms for non-working apparatus was con-ducted, creating matrix $\mathrm{X}_{2}, \mathrm{X}_{3}$, etc. which corresponded to specific damage responsible for such courses. The whole learning set, based on which new observations were qualified, in its simplest version, has four classes: $\mathrm{C} 1$ - working injection apparatus, $\mathrm{C}_{2}$ - improper adjustment of injector spring, $\mathrm{C}_{3}$ - leaky atomizer nozzle, $\mathrm{C}_{4}$ - other damage (Fig. 5 shows classification for two classes, fitness and unfitness for use of the injection apparatus). 


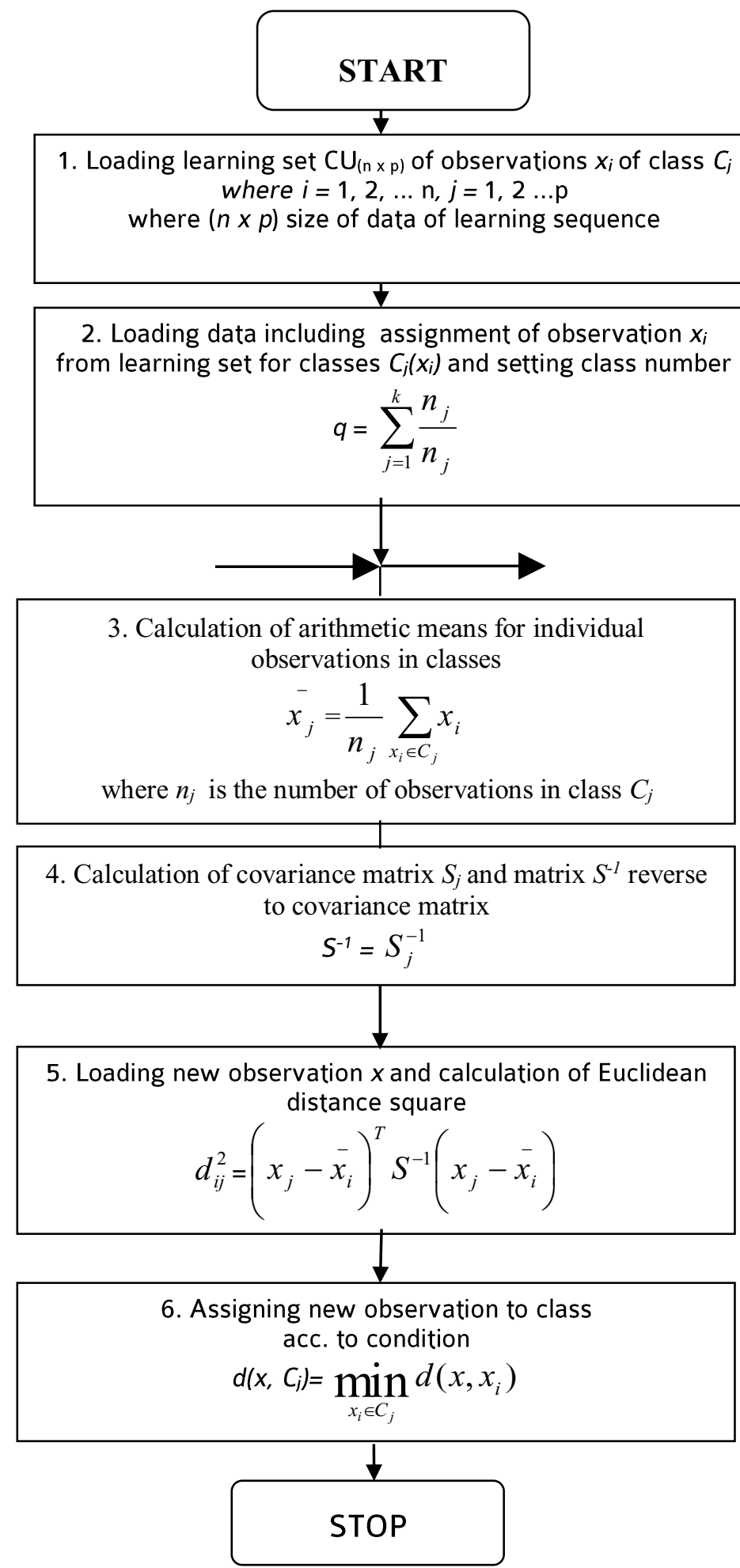

Fig.6. Algorithm of assigning new observation to class from learning set [5] 


\section{Summary}

Only in few cases, the designers of expert systems created on skeleton systems are able to limit themselves to the tools proposed by the given skeleton system. When the created advisory system must be able to solve specialist issues with high complexity, it is necessary to refer to other specialist solutions.

The rather well known and discussed method for observation of fuel pressure oscillograms in the injection conduit is limited during the engine test to classification of the technical condition based on operator's knowledge and experience.

The proposed solution for recognition of the injection apparatus by recognizing the condition of fuel injection high pressure systems and equipping the advisory system with them, will allow to eliminate often subjective opinions on the technical condition of engines fitted with injection apparatus.

\section{References}

1. Basztura Cz.: Jak rozmawiać z komputerem ludzkim głosem?, WPN Format, Wrocław (1993)

2. Cholewa W., Pedrycz W.: Systemy doradcze, Skrypt uczelniany Politechniki Ś lą skiej nr 1447, Gliwice (1987)

3. Jankowski M.: Ocena wraż liwoś ci diagnostycznej sygnału pulsacji ciś nienia aparatury wtryskowej. Praca doktorska. Bydgoszcz, (1997)

4. Kramarenko G.; Techniczna eksploatacja samochodów. WKŁ. Warszawa, (1989)

5. Kupraszewicz 'W.; Ż ółtowski B.: Wykorzystanie układu szkieletowego w diagnostyce silnika. Materiały konferencyjne AIRDIAG (1999)

6. Ostasiewicz S.; Statystyczne metody analizy danych; WAE Wrocław, (1999)

7. Tadeusiewicz R., Wszołek W., Izworski A.: Zastosowanie sieci neuronowej oraz rozpoznawania obrazów w diagnostyce mowy zdeformowanej, Materiały konferencyjne, Mię dzynarodowy Kon-gres Diagnostyki Technicznej KDT'96, Gdań sk (1996)

8. Tylicki H.: Diagnozowanie układu wtrysku paliwa silników spalinowych, Materiały konferencyjne, Diagnostyka'99, KMR i P, ATR Bydgoszcz (1999)

9. Ż ółtowski B,: Podstawy diagnostyki maszyn. ATR Bydgoszcz (1996)

10. Ż ółtowski $B$,: Diagnostyka silnika wysokoprę $\dot{z}$ nego. Instytut Technologii Eksploatacji, Radom, (1995)

11. Ż ółtowski B, Ć wik Z,: Leksykon Diagnostyki Technicznej. ATR; Bydgoszcz, (1996) 